\title{
Healthy pregnancies and essential fats: focus group discussions with Zambian women on dietary need and acceptability of a novel RUSF containing fish oil DHA
}

Catherine Chunda-Liyoka', Mwansa Ketty Lubeya², Mercy Imakando², Sophia Kisling ${ }^{3}$, Sonoor Majid ${ }^{3}$, Mary S. Willis ${ }^{4}$, Charles Wood ${ }^{5}$, Chipepo Kankasa ${ }^{1}$ and Concetta C. DiRusso ${ }^{3 *}$ (i)

\begin{abstract}
Background: Nut butter-based Ready to Use Supplemental Foods (RUSF) are an effective way to add nutrients and calories to diets of malnourished and food insecure populations. The RUSF formulations have been further modified to add micronutrients including iron and folic acid needed during pregnancy and lactation. Because docosahexaenoic acid (DHA, C22:6 n-3) enhances fetal development and birth outcomes, it has been suggested that perhaps RUSF formulations for pregnancy should also include this Omega 3 fatty acid. The goal of the present study was to gain an understanding of Zambian women's knowledge of nutritional needs in pregnancy through structured focus group discussions, and to formulate and determine the acceptability of a RUSF with DHA.

Methods: Structured focus group sessions were conducted among women attending an antenatal clinic at the University Teaching Hospitals in Lusaka, Zambia. Dietary and nutrition knowledge was surveyed through structured dialogue that was recorded by audio and transcribed verbatim. An RUSF containing $400 \mathrm{mg}$ DHA from fish oil in 50 g RUSF was designed and assessed for fatty acid content and product stability. Participants then sampled the RUSFDHA, provided feedback on taste, and were surveyed about willingness to consume the novel formula using a standardized hedonic instrument.

Results: The participants' knowledge of foods recommended for use in pregnancy included fruits, vegetables, meat, and fish. Most women reported eating fish at least once per week, although the specific type of fish varied. Most did not have prior knowledge of the importance of consuming fish during pregnancy or that some fish types were more nutritional than others as they included omega 3 fatty acids. The participants were uniformly accepting of the RUSF-DHA for the purpose of enhancing birth and developmental outcomes, but were critical of the aroma in hedonic testing.

Conclusions: Women were committed to consuming a healthy diet that would impact the outcome of pregnancy, and were receptive to advice on the importance of consuming foods such as fish as a source of DHA. The RUSFDHA formulation was acceptable due to the potential benefits for the developing infant, however, the fishy odor may be limiting for long-term daily use.
\end{abstract}

Keywords: Ready to use supplemental foods (RUSF), Docosahexaenoic acid (DHA), Omega 3, Focus groups, Hedonic assessment, Malnutrition, Food insecurity, Zambia, Pregnancy

\footnotetext{
* Correspondence: cdirusso2@unl.edu

${ }^{3}$ Nebraska Center for Integrated Biomolecular Communications, Department of Biochemistry, N241 Beadle Center, University of Nebraska-Lincoln, Lincoln, NE 68588, USA

Full list of author information is available at the end of the article
}

(c) The Author(s). 2020 Open Access This article is distributed under the terms of the Creative Commons Attribution 4.0 International License (http://creativecommons.org/licenses/by/4.0/), which permits unrestricted use, distribution, and reproduction in any medium, provided you give appropriate credit to the original author(s) and the source, provide a link to the Creative Commons license, and indicate if changes were made. The Creative Commons Public Domain Dedication waiver (http://creativecommons.org/publicdomain/zero/1.0/) applies to the data made available in this article, unless otherwise stated. 


\section{Background}

Maternal, infant, and child nutrition is accepted as a key determinant of health that is vital to human capital development and, as such, is a high priority for SubSaharan Africa [1, 2]. Zambia has a population of approximately 16 million and about half of these are women of reproductive age (15-49) [1]. More than a third of women give birth to their first child before age 18 and $50 \%$ by the age of 20 . Additionally, $10 \%$ of women aged 15-49 are underweight (BMI $<18.5 \mathrm{~kg} / \mathrm{m}^{2}$ ), ) and $14.3 \%$ of women in Zambia are living with HIV. Low pre-pregnancy BMI, short stature and HIV are among the risk factors for poor birth outcomes. In the under-five age group, $14.8 \%$ are underweight and $40 \%$ are stunted, with $17 \%$ severely stunted. It is estimated that only $11 \%$ of children aged $6-23$ months are fed adequately based upon recommended feeding practices [1]. About 72,000 children (0-14 years) are infected with HIV. Due to the high rates of both malnutrition and HIV infection in Zambia, it is essential that nutrition be optimized to maximize development, growth, and the ability to resist and fight infectious disease [2, 3].

Improving maternal and infant nutrition and health is a major focus of the Zambian Government to ensure the population reaches its full potential [1, 4]. However, the dietary diversity for women and children in Zambia is highly dependent upon socioeconomic status, such that a low diversity index correlates with malnutrition and food insufficiency [5, 6]. Animal-source foods are limited and the diet is highly dependent on starchy staples such as the corn-based porridge, nshima. Therefore, the basic diet of the very low income population has limited diversity, contributing to insufficient daily protein and micronutrient intake, and minimal consumption of long chain polyunsaturated n-3 fatty acids [1]. Fish is an important staple in the Zambian diet and fish intake correlates with dietary diversity and lower levels of stunting [2, 5, 7]. The small sardine-like fish species, kapenta, are a rich source of DHA and native to Zambia [7]. However, in recent years, fish has become expensive and availability more limited, especially in urban Zambia where the bulk of the population resides.

In cases of undernutrition, intervention and recovery programs can help to improve nutritional status. These often include Ready to Use Therapeutic Foods (RUTF) that are formulated to treat moderate (MAM) and severe acute malnutrition (SAM) $[8,9]$. The base of one class called lipid nutritional supplements (LNS) is nut paste, generally peanut butter, that is supplemented to meet daily macro- and micro-nutrient requirements including the essential fatty acids $[8,10,11]$. When first developed, the sole purpose of these lipid based RUTFs was shortterm use in SAM to raise the individual's body weight over 3-4 weeks after which the patient could be transitioned to a conventional diet [10]. In actuality, due to pervasive malnutrition and food insecurity, the therapeutic foods are used over months to supplement the diet of children with MAM and SAM under the age of five and pregnant or lactating women [11, 12]. This has led to the development of Ready to Use Supplemental Foods (RUSF) that provide the daily requirement for essential micronutrients, and a lesser amount of the macronutrients, to bring added value to the daily food intake and enhance, but not replace, a conventional diet.

One point of concern with the lipid-based RUTFs is that the essential polyunsaturated fatty acids in these food supplements are from plant oils and include only linoleic acid (LA n-6) and linolenic acid (LN n-3). These two fatty acids must be further processed in the body to make the long chain polyunsaturated fatty acids arachidonic acid (AA n-6), eicosapentaenoic acid (EPA n-3) and docosahexaenoic acid (DHA n-3). This biological process is inefficient in humans [13]. Because DHA is a building block for fetal brain growth, large amounts are required during fetal development and for 24 months after birth [14]. When a pregnant woman is food insecure, her fetus, and later her infant, are at risk for suboptimal brain development and function. If both food insecure and living with HIV, fetal brain development and function are further at risk $[2,15,16]$. Therefore, there is much interest in developing dietary supplements that include DHA, during pregnancy and lactation, to support neuronal development $[17,18]$.

Given the high rate of malnutrition and stunting in Zambia and the value of RUSF for use in addressing some of the nutritional problems of women and their infants, we developed an RUSF with fish oil to supply the DHA crucial to fetal and infant brain growth. The goals of the present study were to assess the knowledge of pregnant women about what foods are required during pregnancy for maximizing fetal development and, more specifically, to address knowledge about the need for essential fatty acids including DHA in the diet for brain development. Employing focus group discussions surrounding nutrition and health, as well as hedonic testing of the RUSF-DHA, the current study presents findings on nutrition knowledge for pregnancy and the acceptability the peanut butter-based RUSF with fish oil to pregnant women in Zambia.

\section{Methods}

\section{Study site}

This work was a collaboration between the University Teaching Hospitals (UTHs), Lusaka, Zambia and the University of Nebraska, Lincoln, Nebraska, U.S.A. Experimental design, ethical conduct of the research, and the data sharing plan were approved by Institutional Review Boards at each institution to comply with Zambian 
and US laws (UNZAREC IRB \#00005948 and UNL IRB \#20170416833FB). Experimental design met NIH policies regarding conflict of interest, biosafety, human participant research, data collection and analysis, and confidentiality.

This study took place in Lusaka, Zambia, at the UTHs, which are part of a complex of hospitals that include the Women and Newborn Hospital, Children's Hospital, Adult and Emergency Hospital, Eye Hospital and Cancer Diseases Hospital. Lusaka is the largest city in Zambia with a population of about 2.4 million inclusive of the metropolitan area, which is $15 \%$ of the total national population. The UTHs comprise the largest health care center in the country. The Women and New Born Hospital of the UTHs facilitate approximately 60-80 antenatal clinic screenings performed per day and 900-1000 deliveries per month, on average, providing a large patient population pool for the studies reported here.

\section{Participants}

All participants were recruited from the antenatal clinic of the Women and Newborn Hospital in Lusaka. The individuals were selected for participation in the focus group at random from a pool of approximately 150 women being recruited for a larger preclinical trial. The participant pool was made up of women of reproductive age who were pregnant and of a typical pre-pregnancy body mass, i.e., between 18 and $25 \mathrm{~kg} / \mathrm{m}^{2}$ and neither over- or under-weight. Referral for participation was made through collaborating medical doctors in the UTH Women and Newborn Hospital antenatal care clinic (ANC). Information about the study was verbally given to potential participants by study nurses and/or doctors. Those that understood and accepted the invitation were asked to provide written informed consent to be included in the study.

\section{Focus group site and procedures}

The sessions were held in the ANC meeting and training room. The room was an open space with rows of benches used for antenatal lessons and clinic appointment registration holding about $60-80$ persons at capacity. The focus groups were held at times when the room was not scheduled for other purposes. However, the outside entrance was at the back of the room, consequently, some individuals who were not participating could enter or exit during focus group sessions. The number of non-participants never exceeded 5-10 and these individuals stayed at the back of the room away from the discussions. Non-participants were instructed to remain silent during session conversations.

Three focus group sessions with 7-10 participants (totaling 27) were held on 3 different days between September and November 2017. This number was considered adequate to engage participants in a conversation without inhibiting more reticent individuals [19]. A core team of professionals ran the sessions and included two physicians (authors MKL and MI), one study nurse and one nutritionist. All had experience in conducting sessions of this type for the purpose of teaching and research. Only the nutritionist was male, and although session leadership roles varied, the same professionals participated in all 3 sessions using the same script. The predominant language used during focus groups was Nyanja with some English, which was understood by most participants. In one of the groups, there was a client who could not understand Nyanja/English, so Bemba had to be used as well. An audio recording was made of each session after informing the clients that discussions would be recorded. The 3 session recordings were translated to English by a professional translator and verified by one investigator (MKL). Additionally, a video recording was made of one session for archival purposes.

\section{Focus group discussion guides}

The transcript of the focus group discussion is available in Additional file 1 and is outlined in Table 1. Briefly, the introduction welcomed the participants and instructed them on the purpose of the meeting, the manner in which discussions were to be conducted, and explained that the sessions would be recorded by audio taping. Then the discussion proceeded around questions about food consumption patterns and nutritional intake during pregnancy, as well as the intake of fish. Subsequently, the RUSF-DHA was offered for hedonic assessment and discussion of probable acceptance and use as a dietary supplement in pregnancy.

\section{Analysis of Focus Group Responses.}

The transcripts from the 3 focus group sessions were assessed independently by 3 of the study investigators using content analysis methods [20]. The coding units were established a priori for the quantitative data and the script of the sessions was based on the various categories developed into questions as listed in Table 1. Coding centered on 4 themes: knowledge of nutritional needs in pregnancy; knowledge of fish intake for omega 3 DHA consumption; familiarity with RUSF; acceptability and palatability of new RUSF-DHA. After the 3 analysts rated the responses independently, a summative response database was generated and then employed to yield Table 2 .

To assess the acceptability of the RUSF-DHA, each participant was offered a $50 \mathrm{~g}$ sachet to taste the product and asked to verbally express their response for aroma, texture, flavor, aftertaste, and overall attributes. Each participant also recorded their response on a 9-point hedonic testing instrument. The data were assessed using least squares means. 
Table 1 Layout of the Interview Guide

\begin{tabular}{|c|}
\hline 1. Introduction \\
\hline 1.1. Welcome and thank the participants for their participation \\
\hline 1.2. Introductions of the discussion leader and observers \\
\hline 1.3. Describe the purpose of the Focus Group and DHA discussion \\
\hline 1.4. Establishing ground rules for the discussion \\
\hline $\begin{array}{l}\text { 1.5. Informing about session recording by audio only or audio and } \\
\text { video }\end{array}$ \\
\hline 2. Questions regarding food and nutrition during pregnancy \\
\hline $\begin{array}{l}\text { 2.1. Are there any special foods purchased or prepared especially for } \\
\text { pregnant women? }\end{array}$ \\
\hline 2.2. Do pregnant women need to take vitamins? \\
\hline 2.2.1. Why or why not? \\
\hline 2.3. How many of you are taking vitamins while you are pregnant? \\
\hline 2.4. Where do you get them? Do you pay for them or are they free? \\
\hline $\begin{array}{l}\text { 2.5. Are there any foods that women should not eat when they are } \\
\text { pregnant? Why? }\end{array}$ \\
\hline $\begin{array}{l}\text { 2.6. What should women eat to stay healthy when they are } \\
\text { breastfeeding? }\end{array}$ \\
\hline 3. Questions regarding fish intake \\
\hline 3.1. Do you eat Kapenta and fish? \\
\hline 3.2. How often do you buy Kapenta and fish in your home? \\
\hline 3.3. How often do you eat it in a week? \\
\hline 3.4. What type of fish and Kapenta do you eat? \\
\hline $\begin{array}{l}\text { 4. Questions regarding RUSF (asked while smelling and tasting the } \\
\text { product). }\end{array}$ \\
\hline 4.1. Do you have any allergies to the ingredients in the packet? \\
\hline 4.2. How does it taste? \\
\hline $\begin{array}{l}\text { 4.3. Do you think other pregnant and breastfeeding women would } \\
\text { like it? }\end{array}$ \\
\hline 4.3.1. Why or why not? \\
\hline $\begin{array}{l}\text { 4.4. How often would a pregnant or breastfeeding mother eat a } \\
\text { product like this? }\end{array}$ \\
\hline 4.5. How do you think you might eat this product? \\
\hline 4.6. What foods might you eat it with or mix it with? \\
\hline 4.7. What do you like about the product? \\
\hline 4.8. Any problems or disadvantages with this product? \\
\hline 4.9. What could be changed about it? \\
\hline 4.10. Overall, do you like this product? \\
\hline $\begin{array}{l}\text { 5. Please fill out the questionnaire (i.e. hedonic survey) about the } \\
\text { oroduct. }\end{array}$ \\
\hline
\end{tabular}

\section{Formulation and analysis of the RUSF-DHA}

The Ready to Use Supplemental Food with DHA (RUSF-DHA) formulation was based on World Health Organization guidance [8]. The base was peanut butter and supplements were formulated as in iLiNS [21]. A dosage of $400 \mathrm{mg}$ DHA in $50 \mathrm{~g}$ RUSF was selected, based on previous studies that recommended this level of DHA to maximize birth outcomes [22]. To supply this level of DHA, the RUSF was supplemented with $5.22 \%$ Meg- $3^{\text {тм ' }} 30$ ' n-3 Food Oil, a highly refined tuna oil that has a minimum of 9\% EPA and 12.5\% DHA (DSM Nutritional Products, Inc.). The formulation was prepared in the factory of Edesia Nutrition, Inc. (Kindstown, RI) and transported to Zambia by express shipping.

Each batch of RUSF-DHA was evaluated for fatty acid content after Folch extraction, acid hydrolysis and conversion to methyl esters using gas chromatography and mass spectrometry as is standard in the DiRusso laboratory [23]. A commercial thiobarbituric acid reactive substances (TBARS) analysis kit was used to measure lipid peroxidation (Sigma-Aldrich, St. Louis, MO, USA) of the RUSF-DHA product.

\section{Results}

Focus group assessment regarding dietary practices and knowledge of nutrition

Participants were enrolled during antenatal clinic visits for sessions being held that day. In total, 3 sessions were convened. Twenty seven women, 7 in the first session, and 10 in sessions two and three, participated in the focus group and subsequent RUSF-DHA taste test. All participants were between 18 and 41 years of age, 16 to 34 weeks of gestation, and 18 to $25 \mathrm{~kg} / \mathrm{m}^{2}$ of body mass index. Approximately $50 \%$ of the women had completed secondary schooling, while $18 \%$ had completed only primary school. The remaining participants had some tertiary education and training. An outline and summary of the Interview Guide procedures and questions for the discussions are presented in Table 1 and the complete focus session transcript appears in Additional file 1.

The knowledge of the participants regarding nutritional needs during pregnancy was assessed by querying information about what special foods and supplements including vitamins should or should not be ingested during pregnancy. There was a general consensus in each focus group session that non-fatty foods, dairy products as a source of calcium, and foods containing iron should be consumed on a daily basis (Table 2). The foods cited as containing these nutrients included milk, yogurt, liver, fish or kapenta. Other foods noted that should be eaten during pregnancy included fruits and vegetables, ground nuts, beans and nshima, a corn-meal based porridge that is a staple of the local diet.

All participants acknowledged that vitamin supplements are recommended during pregnancy for the health of the child, and further reported that these were provided at no cost at the antenatal clinic or might be purchased at a pharmacy. Referring to the free vitamin supplements, one participant commented that,

"Yes, always when someone is pregnant they are given vitamins although we can't know what they do 


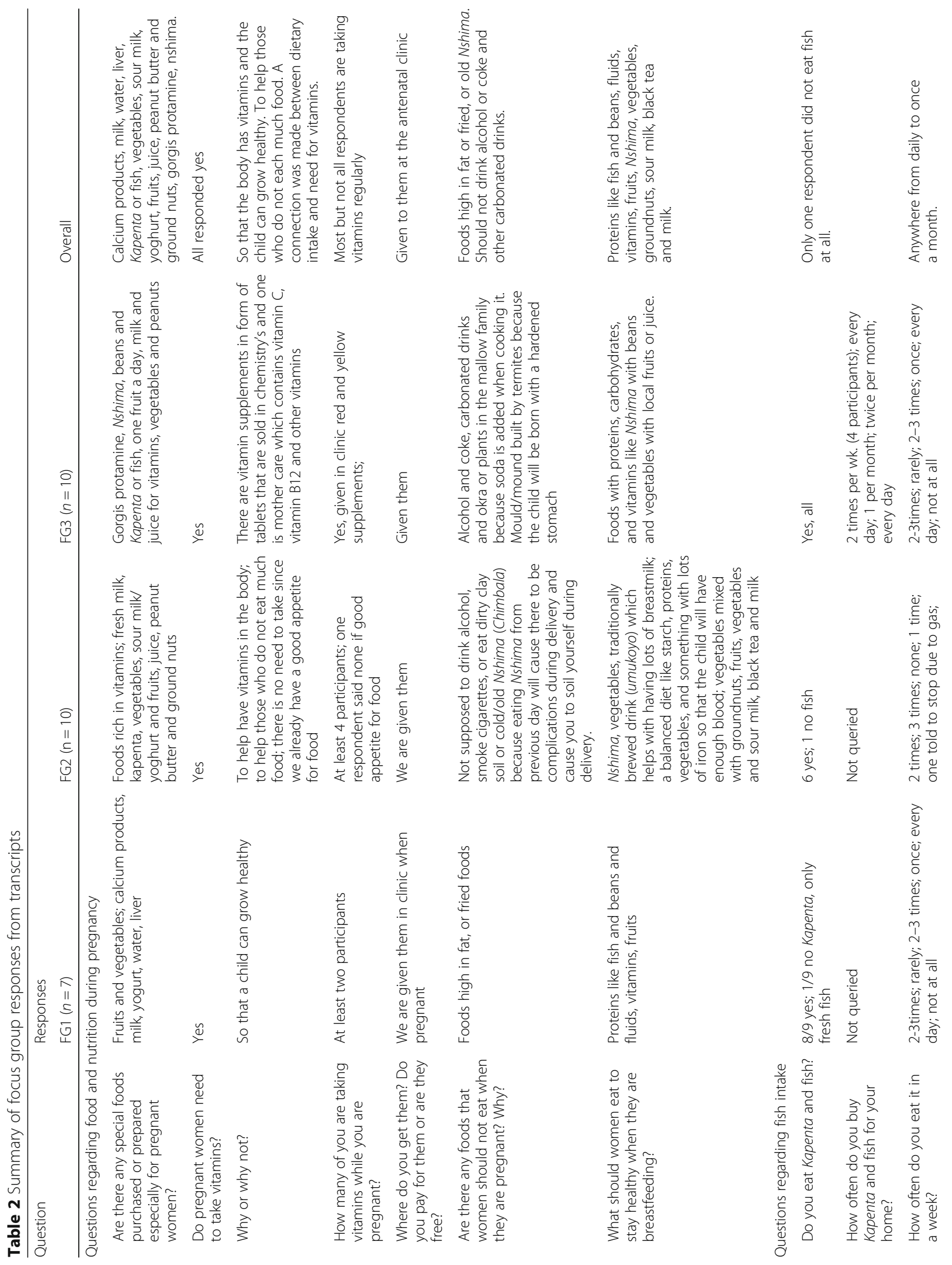




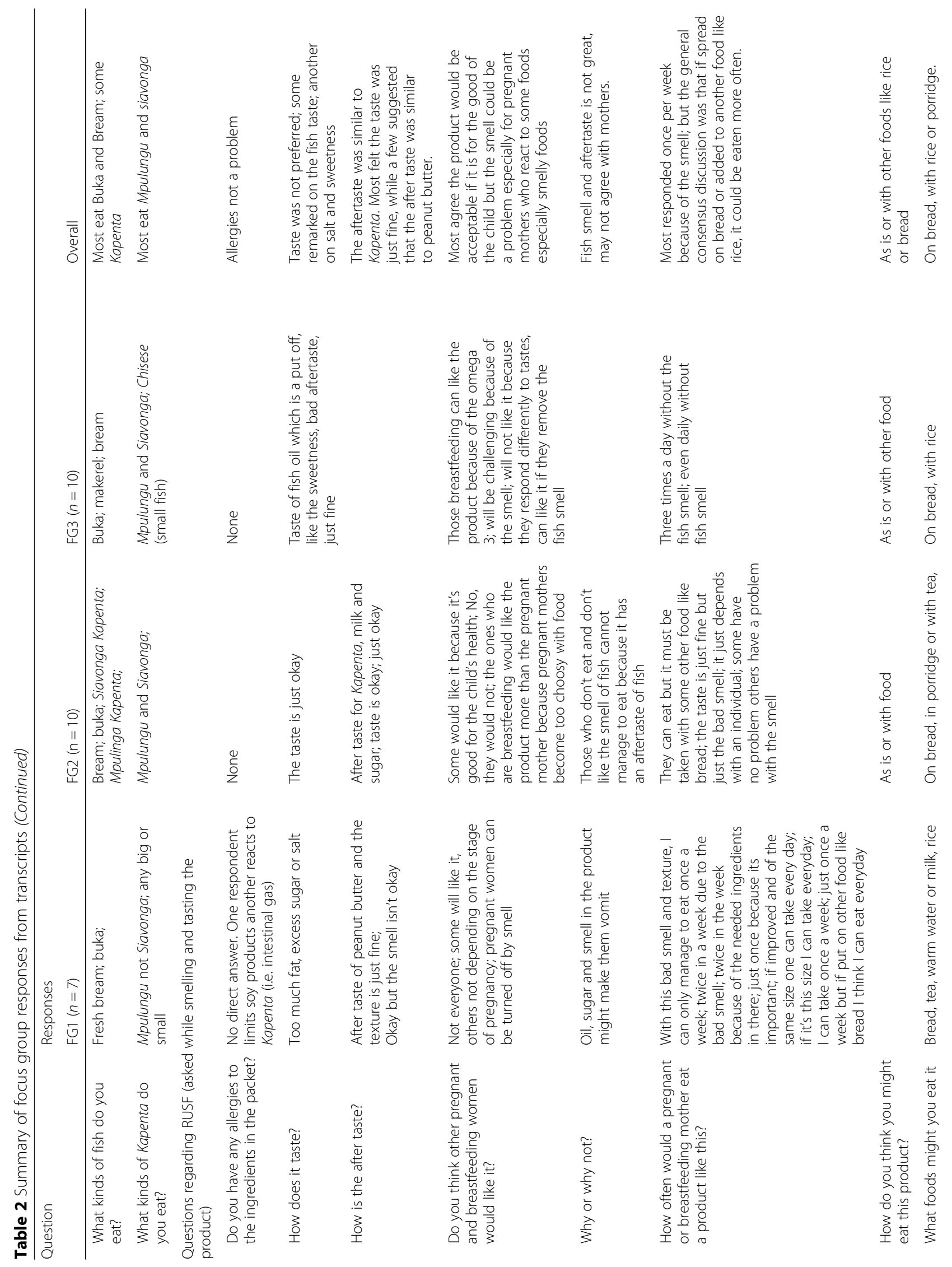




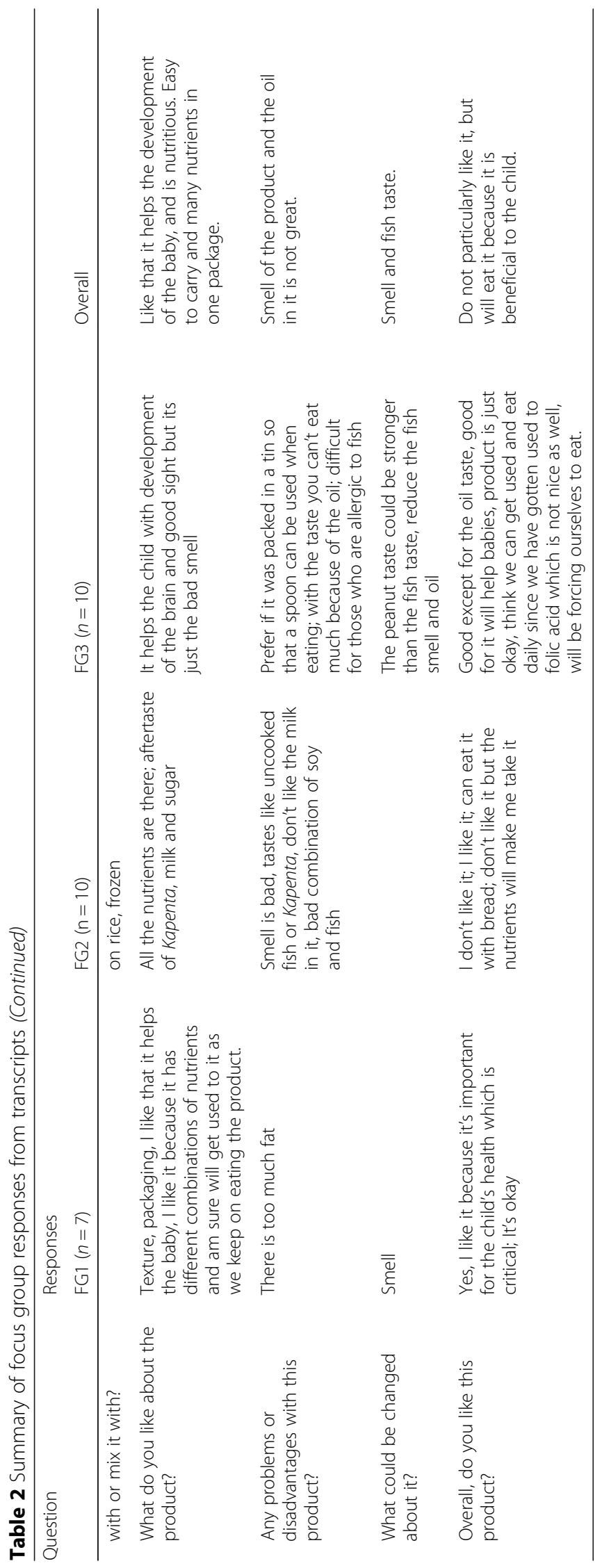


with them at home whether they throw or they take them". F01-R1

There was a general acknowledgement that vitamins are particularly important when food is limited on a daily basis. Specific vitamins mentioned included vitamin C and B12. A need for calcium and iron supplementation was mentioned in two of the sessions. However, despite the access and knowledge about vitamins, not every woman was taking them daily. A respondent stated,

"... there is no need to take since we already have a good appetite for food". F02-R1

Participants indicated that some foods and beverages should be avoided, including those that are high in salt and fat, soft drinks, and alcohol. Smoking was also discussed for its negative health impacts. One participant commented that,

\section{"she can eat anything unless if its causing her to have nausea." F01-R2}

This comment initiated a discussion of the negative impact on appetite of strong odors and flavors during pregnancy. There was also a discussion in one group about the practice of eating dirt or clay, a practice that is common in some cultures [24-26]. The participants acknowledged that this practice was discouraged by healthcare workers.

\section{Assessment of fish consumption and knowledge of health benefits of fish}

Certain fish species are a natural nutritional source of DHA [7, 27]. Therefore, fish intake was extensively queried and discussed. Those participants that ate fish did so on average 2-3 times per week; one participant said she eats it every day and one did not eat fish at all. Fish was acknowledged as being a good nutritional staple during pregnancy, but not specifically as related to brain or cognitive development of the fetus or infant. That information was provided by the focus group facilitators as part of the introduction describing the purpose of the focus group and importance of DHA intake for infant development (Additional file 1). The common fish species purchased and consumed were: bream made up of common types of cichlidae similar to tilapia; mpulungu buka (Lates stappersi); kapenta, a type of fresh water sardine (Limnothrissa miodon and Stolothrissa tanganicae); and chisense (Neobola nweruensis). One participant mentioned eating mackerel. Of these, kapenta, chisense and mackerel contain significant amounts of DHA $(10 \%$ or more of the total fatty acids) [7, 27]. Kapenta intake was specifically queried in the survey for this reason. Intake varied from none to 2-3 times per week. It should be noted most respondents who ate fish generally mentioned bream and buka, which are not significant sources of DHA [27, 28].

\section{RUSF formulation}

A major goal of this work was to develop and assess an RUSF to contain fish oil as a method to deliver macronutrient and micronutrient supplements and DHA to women at risk for food insecurity and malnutrition during pregnancy and lactation since this is a concern in Zambia [5, 29]. The lipid based nutrient supplements are deemed a valid delivery vehicle for DHA as the oils are miscible in the nut paste, low in water, as well as air and light tight, which helps to maintain the integrity of the highly unsaturated fatty acids to prevent or reduce oxidation [30]. The base of the RUSF-DHA developed for this study was peanut butter, supplemented with non-fat milk and whey powders, sugar, and mixed natural tocopherols as preservatives with a vegetable oil mixture as listed in Table 3. Additional micronutrients, including minerals and vitamins, were added as recommended [8]. Preliminary formulation tested DHA levels at 300,600 or $900 \mathrm{mg}$ per 20,50 or $75 \mathrm{~g}$ of RUSF. We sought the highest dose palatable, based on aroma and taste in small group tastings at Edesia, Inc. and UNL. The 300-600 mg doses were equally accepted, while the $900 \mathrm{mg}$ dose was rated as having the strongest "fishy" odor and aftertaste. The final formulation of approximately $400 \mathrm{mg}$ DHA per $50 \mathrm{~g}$ supplement was selected to reach levels informed by studies in the US and elsewhere as suitable for optimal birth and infant developmental outcomes [14, 22, 31-35].

Fatty acid analysis of the final product indicated about half of the fat was monounsaturated, primarily oleic acid and about $13.5 \%$ was the saturated fatty acid palmitate (Table 4). The polyunsaturated fatty acids (PUFA) (linoleate and linolenate) comprised about $50 \%$ of the total fatty acids and the long chain highly unsaturated PUFA were $3 \%$ total. As expected of the latter, arachidonic acid levels were low at $0.24 \mathrm{~mol} \%$ since an enriched source of this long chain PUFA was not added, while EPA and DHA were 0.57 and $2.3 \mathrm{~mol} \%$ total FA, respectively, from the fish oil. Since oxidation of DHA and other unsaturated fatty acids could lead to reduced palatability and unfavorable odors (i.e. "fishiness"), a commercial assay was performed, which demonstrated no significant increase in oxidized lipids over 6.5 months storage with temperature (Fig. 1).

\section{Comments on the RUSF-DHA while sampling the food}

After the discussion of diet and nutrition information, the participants were offered a $50 \mathrm{~g}$ sachet of the RUSF-DHA to taste, smell, and sample. Impressions of the food product were recorded and transcribed from the discussions 
Table 3 Composition of the RUSF-DHA (50 g serving)

\begin{tabular}{|c|c|c|}
\hline Ingredients & Contents & \\
\hline & $\begin{array}{l}\text { Non-hydrogenated vegetable oil (containing soybean } \\
\text { oil, canola oil, palm oil), peanuts, nonfat milk powder, } \\
\text { sugar, whey powder, Meg-3'3 ' } 30^{\prime} \text { ' n-3 INF Oil (refined } \\
\text { fish oil from tuna), identity preserved mixed natural } \\
\text { tocopherols, ascorbyl palmitate, stabilizer (hydrogenated } \\
\text { vegetable fat), and vitamin and mineral complex. }\end{array}$ & \\
\hline & Amount $/ 50 \mathrm{~g}$ & $\mathrm{kcal} / 50 \mathrm{~g}$ \\
\hline Fat & $20.4 \mathrm{~g}$ & 184 \\
\hline Protein & $6.8 \mathrm{~g}$ & 27 \\
\hline Carbohydrate & 21.4 & 86 \\
\hline Calories & & 297 \\
\hline Meg-3'⿳一 '30' n-3 INF Oil & $5.22 \%$ (400 mg DHA) & \\
\hline Iron & $22 \mathrm{mg}$ & \\
\hline Vitamin C & $90 \mathrm{mg}$ & \\
\hline Folic Acid & $600 \mathrm{mcg}$ & \\
\hline lodine & $330 \mathrm{mcg}$ & \\
\hline Water Activity & 0.367 & \\
\hline Enterobacteriaceae & $<10 \mathrm{cfu} / 10 \mathrm{~g}$ & \\
\hline Salmonella & $0 \mathrm{cfu} / 375 \mathrm{~g}$ & \\
\hline Total Aflatoxin & $<0.2 \mathrm{ppb}$ & \\
\hline
\end{tabular}

RUSF-DHA formulation by Edesia Nutrition, Inc., Kingstown, RI. Note, not all micronutrients listed

Table 4 Fatty acid analysis of RUSF-DHA

\begin{tabular}{|c|c|c|c|c|c|}
\hline \multirow[b]{2}{*}{ Fatty Acid } & & \multirow[b]{2}{*}{$\mathrm{RT}\left(\mathrm{T}_{0}\right)$} & \multicolumn{2}{|c|}{$\mathrm{mg} / 50 \mathrm{~g}$ Serving $(\mathrm{SEM})^{1}$} & \multirow[b]{2}{*}{$40^{\circ} \mathrm{C}\left(T_{6.5}\right)$} \\
\hline & & & $\mathrm{RT}\left(\mathrm{T}_{6.5}\right)$ & $30^{\circ} \mathrm{C}\left(\mathrm{T}_{6.5}\right)$ & \\
\hline Myristic & C14:0 & $74.2(2.71)$ & $77.06(2.55)$ & $75.13(1.50)$ & $73.77(1.34)$ \\
\hline Palmitic & C16:0 & $1762(34.92)$ & $1860.6(28.97)$ & $1716.44(7.96)$ & $1708.17(17.2)$ \\
\hline Palmitoleic & C16:1 & $94.73(2.32)$ & $100.30(0.53)$ & $96.59(2.47)$ & $97.31(1.53)$ \\
\hline Stearic & C18:0 & 771.07 (14.09) & 810.53 (11.99) & $763.54(2.78)$ & $756.51(3.85)$ \\
\hline Oleic & C18:1 & $7032.46(172.12)$ & 7535.15 (83.29) & $6895.01(124.53)$ & $6870.18(130.09)$ \\
\hline Linoleic & C18:2 n-6 & $2490.37(52.82)$ & $2639.32(26.96)$ & $2510.33(54.07)$ & $2523.96(37.58)$ \\
\hline Linolenic & C18:3 n-3 & $787.94(16.77)$ & $827.30(9.78)$ & $806.42(21.66)$ & $816.78(9.97)$ \\
\hline Arachidonic & $C 20: 4 n-6$ & $36.89(0.95)$ & $36.9(1.03)$ & $36.43(1.80)$ & $35.57(0.29)$ \\
\hline Eicospentaenoic & $C 20: 5 n-3$ & $84.34(2.61)$ & $91.1(1.37)$ & $87.43(2.20)$ & $88.51(1.17)$ \\
\hline \multirow[t]{2}{*}{ Docosahexaenoic } & $C 22: 6 n-3$ & $375.52(11.79)$ & $386.50(11.69)$ & $402.38(10.70)$ & $405.17(5.83)$ \\
\hline & & & Relative mol\% & & \\
\hline SFA & $\mathrm{C} 14+\mathrm{C} 16+\mathrm{C} 18$ & $19.61(0.08)$ & $19.44(0.07)$ & $19.36(0.24)$ & $19.26(0.14)$ \\
\hline MUFA & $\mathrm{C} 16: 1+\mathrm{C} 18: 1$ & $50.1(0.2)$ & $50.49(0.06)$ & $49.49(0.18)$ & $49.35(0.19)$ \\
\hline PUFA & $C 18: 2+C 18: 3$ & $23.21(0.07)$ & $23.09(0.04)$ & $23.64(0.17)$ & $23.83(0.03)$ \\
\hline HUFA & $C 20: 4+C 20: 5+C 22: 6$ & $3.08(0.04)$ & $3(0.05)$ & $3.28(0.04)$ & $3.3(0.02)$ \\
\hline$n-6: n-3$ & & $2.11(0.01)$ & $2.14(0.01)$ & $2.05(0.02)$ & $2.04(0.04)$ \\
\hline
\end{tabular}

${ }^{1} \mathrm{RT}$, room temperature; 6.5 indicates the number of months in storage at the indicated temperature. SFA, saturated fatty acid; MUFA, monounsaturated fatty acid; PUFA, polyunsaturated fatty acid; HUFA, highly unsaturated fatty acid 


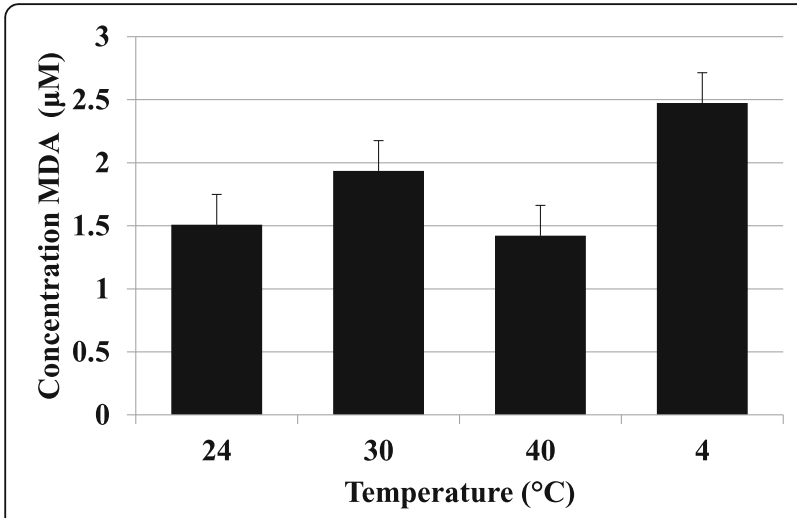

Fig. 1 Estimation of lipid peroxidation after storage. RUSF-DHA samples were stored at various temperatures for 6.5 months. There is no significant difference between samples (One way ANOVA ( $p=$ 0.69; JMP Pro v12))
(Table 2) as well as recorded in a standardized hedonic test (Table 5). None of the participants had any noted allergies to the product ingredients, although one indicated a problem with intestinal gas after eating dried fish and another said she generally limits soy products. The most negative remarks revolved around the aroma, which was felt to be too "fishy". For example, remarks included:

"the taste is just fine only the smell is what I don't like". F03-R5

Most participants felt the taste was acceptable, although a few thought the taste was salty and sweet, which is a common response of adults to lipid-based RUTFs. The texture was acceptable to all.

The participants were asked how often they thought a pregnant or breastfeeding mother would eat this product.

Table 5 Summary of focus group responses to sensory test (27 participants)

\begin{tabular}{|c|c|c|c|}
\hline Attribute & $\begin{array}{l}\text { Hedonic Scale* Mean } \\
\text { (Range) }\end{array}$ & Oral Comments & Written Comments \\
\hline \multirow[t]{5}{*}{ Aroma } & \multirow[t]{5}{*}{$4.41(1-9)$} & Don't like the fish smell & Aroma needs to be changed \\
\hline & & \multirow[t]{4}{*}{ Bad smell } & Smell is unfavorable \\
\hline & & & Aroma is not very appealing \\
\hline & & & There is a fish smell \\
\hline & & & Aroma should be changed \\
\hline \multirow[t]{2}{*}{ Texture } & \multirow[t]{2}{*}{$8.30(4-9)$} & \multirow[t]{2}{*}{ It's okay, smooth and thick } & Texture is OK \\
\hline & & & Texture is good \\
\hline \multirow[t]{3}{*}{ Flavor } & \multirow[t]{3}{*}{$7.07(2-9)$} & Taste is just fine & Flavor is OK \\
\hline & & \multirow{2}{*}{$\begin{array}{l}\text { If the peanut butter taste were stronger than the fish it could } \\
\text { be much better }\end{array}$} & Flavor is moderately nice \\
\hline & & & Like all of the flavors \\
\hline \multirow[t]{3}{*}{ Aftertaste } & \multirow[t]{3}{*}{$4.11(1-9)$} & Bad aftertaste of fish & Aftertaste is OK \\
\hline & & \multirow[t]{2}{*}{ Peanut butter aftertaste } & Aftertaste is unfavorable \\
\hline & & & Aftertaste is not very nice \\
\hline \multirow[t]{6}{*}{ Overall } & \multirow[t]{6}{*}{$7.11(1-9)$} & $\begin{array}{l}\text { Pregnant and breastfeeding mothers can take it because it's } \\
\text { good for the child's health }\end{array}$ & Sugar level is too much \\
\hline & & Would eat daily without the fish smell & I like the product and everything is okay \\
\hline & & \multirow{4}{*}{$\begin{array}{l}\text { It is good because it helps the child with development of the } \\
\text { brain and good sight }\end{array}$} & They are all fine. It has the benefit for my baby. \\
\hline & & & The product is okay \\
\hline & & & It has got all the vitamins we need \\
\hline & & & $\begin{array}{l}\text { The sample is generally good as it seems to } \\
\text { contain all nutrients }\end{array}$ \\
\hline \multirow{2}{*}{$\begin{array}{l}\text { Likes } \\
\text { overall }\end{array}$} & \multirow[t]{2}{*}{$7.64(6-9)$} & The peanut butter taste & Like it because it has good advantages \\
\hline & & The product helps the child & $\begin{array}{l}\text { The product is okay if the fish smell can be } \\
\text { reduced }\end{array}$ \\
\hline \multirow{3}{*}{$\begin{array}{l}\text { Dislikes } \\
\text { overall }\end{array}$} & \multirow[t]{3}{*}{1 (1 respondent) } & \multirow[t]{3}{*}{ Fishy/oily taste and smell } & Aftertaste is not great \\
\hline & & & Smell is fishy \\
\hline & & & Texture is too thick \\
\hline
\end{tabular}

Least squares means for the aroma, texture, flavor, aftertaste, and overall attributes of the RUSF using a 9-point hedonic scale, ${ }^{*}$ where $9=$ Like Extremely, $8=$ Like Very Much, 7 = Like Moderately, $6=$ Like Slightly, $5=$ Neither Like nor Dislike, $4=$ Dislike Slightly, $3=$ Dislike Moderately, $2=$ Dislike Very Much and $1=$ Dislike Extremely. Attributes were assessed by focus group participants 
The answers varied from only once per week, because of the smell, to three times a day if the fish odor could be limited. Most participants agreed that the RUSF-DHA would be more likely to be acceptable for every day intake if mixed with another food such as rice or eaten as a spread on bread.

While many participants expressed some concern about the smell and flavor, it was generally agreed that the health benefits to the developing child would take precedence over taste and smell to drive the individuals toward acceptance. In hedonic testing, the flavor actually rated quite high at $7 / 9$, while the aftertaste was rated as moderate at $4 / 9$ on a scale of 9 (like extremely) to 1 (dislike extremely) (Table 4). Generally, the participants agreed that if the RUSF-DHA provided nutritional benefit to the child's development, then it would be acceptable to pregnant and lactating women. One stated,

"I like it because it's important for the child's health which is critical, mothers should take it", F01-R6

and another,

"I don't like it but just the nutrients will make me take it." F02-R6

Additionally, it was mentioned that the smell might be less objectionable during lactation, rather than during pregnancy when certain foods and odors can initiate nausea:

"I think the ones who are breastfeeding can like the product more than the pregnant mothers because pregnant mothers become too choosey with food." F02-R3

\section{Discussion}

In the present work, we interrogated knowledge about nutrition during pregnancy and eating habits of pregnant women in an antenatal clinic population in Zambia where there are high rates of food insecurity, malnutrition, and stunting. We also developed and evaluated acceptability of a lipid based-RUSF formulation that contained fish oil to provide a source of DHA. The RUSF-DHA was designed for use by malnourished women during the first 1000 days, from conception through 24 months, during the critical period of brain and neuronal development [14]. The DHA dosage was based on studies in the U.S. and elsewhere that were aimed at evaluating DHA for improved birth, cognitive, and developmental outcomes for women and their infants [15, 34, 36-38].

During the focus group sessions, participants generally expressed knowledge that certain food groups are required for the health of the developing child, including vegetables, fruit, milk and dairy products, beans, corn meal porridge, meat, and fish. The responses reflected the fact that the importance of a nutrient-rich diet during pregnancy was generally acknowledged. Nutrition counseling is routinely incorporated as part of the prenatal program offered by the UTH ANC in Lusaka. Thus, the women were receptive of a relatively new concept that certain fats, namely DHA, were also important for brain development of the child before and after birth. In fact, the value of the nutrient, DHA, drove the acceptability of the RUSF, even though the sensory testing revealed a dislike for the smell of the food and some aspects of the taste including an aftertaste.

Since the supplement should be consumed daily over months during pregnancy and lactation, we also sought to determine acceptability in a population at high risk for food insecurity. The final formulation contained approximately $400 \mathrm{mg}$ DHA per $50 \mathrm{~g}$ serving. The most common criticisms of the product were that it had a fishy smell and taste. Despite this finding, the product was found to be acceptable because of its potential value to healthy birth and developmental outcomes for the child. Ultimately, the development of the child took precedence over the mothers' tastes. It was generally agreed that the $50 \mathrm{~g}$ supplement would be consumed for this reason, especially if added to another component of a standard diet such as rice or bread.

It is noteworthy to mention that, while the RUSFDHA product was designed for use by individuals at risk for chronic malnutrition, the participants in this study were not clinically malnourished as all fell within the range of body-mass index (BMI) between 18 and 24 prepregnancy. However, the need for the product by this clinic population overall is justified as it was determined during enrollment that within the general client base of the clinic, 23\% (168/735) of women visiting for the first prenatal screening were clinically malnourished with a pre-pregnancy $\mathrm{BMI} \leq 16$. The national population average in Zambia for malnutrition is $17 \%$, thus these malnourished women were excluded from the focus group panels to meet the inclusion criteria. However, the malnourished population is the ultimate target for the RUSF being developed to provide one supplement that will meet all the various micronutrient needs of women during pregnancy and lactation [24]. Additional studies are underway in Zambia to assess the DHA status of pregnant women and to examine the possible additional consequences of infectious disease including Human Immunodeficiency Virus (HIV) where prevalence is $22 \%$ of pregnant women [1].

Both women and children diagnosed with severe or moderate malnutrition have positive outcomes when provided Ready to Use Therapeutic or Supplemental Foods (RUTF and RUSF, respectively) as part of their 
therapeutic care $[8,12,24,39,40]$. Studies surrounding such small quantity lipid based nutritional supplements (LNS) were the focus of the International Lipid-Based Nutrient Supplements Project (iLiNS), which sought to evaluate a wide variety of impacts using various formulations of small quantity LNS (i.e. $20 \mathrm{~g}$ total daily) [11]. Encouraging outcomes of some these trials included, for example, increased birth size and length of infants of primiparous women in Ghana taking a small quantity (20 g) RUSF daily from 20 weeks gestation until delivery [21, 41, 42]. Thus, RUSF are often recommended in chronic malnutrition to add essential nutrients to the standard diet during food insecurity. Supplemental feeding projects like the completed Rainbow Project in Zambia further provide evidence for the value of RUTF use [43]. Overall, in the present study the participants displayed a general knowledge of the types of food that are recommended for consumption during pregnancy to provide adequate nutrient intake for mothers and infants. Some of this nutritional advice had been provided by the staff of the ANC during clinic visits. While eating fish to provide specific nutrients like DHA was not necessarily a component of the participants' prior knowledge base, fish are part of the standard diet for the population and are eaten by most 2-3 times per week. However, the type of fish purchased and consumed was variable and some commonly mentioned types including bream and buka that are not a good source of DHA [7, 27].

Common sources of high DHA oils include certain species of fish (e.g. salmon, tuna, sardines) and/or algae [44-46]. In Western cultures, dietary DHA levels are generally very low and dietary supplementation for pregnant and lactating women and infants is highly recommended $[14,16,47]$. No studies have evaluated RUTF or RUSF supplemented with a DHA containing oil and only one has evaluated the combination of RUTF and fish oil capsules in a clinical trial setting [48]. Therefore, it remains controversial as to whether or not there is value in adding DHA and/or limiting the ratio of $n-6$ to $\mathrm{n}-3$ fatty acids to improve health outcomes with these food supplements. Additionally, not all food insecure populations may require DHA supplementation. For example, if the traditional diet includes fish high in DHA as a dietary staple, as is true in Malawi, such supplementation would be unnecessary [49]. Therefore, it will be important to test the need for the product based on assessment of the omega 3 index in blood in the underweight and malnourished population of Zambian women. If low, then supplementation with the RUSF-DHA for outcomes related to fetal and infant development, as well as birth outcomes, must also be evaluated in future studies.

There were limitations to this focus group study, including the small numbers of participants. The size of the groups was kept low at 7-9 individuals to encourage conversation and participation by all members of the group.
The final number at 27 individuals followed recommendations for this type of survey of climate and knowledge surrounding dietary behaviors and knowledge of nutrition [19]. The room chosen for the discussion sessions was also suboptimal as non-participants could not be excluded from the room. The population of participants was limited to the greater urban area of Lusaka. Additional focus groups are planned for rural locations in the future. Language may also have been a barrier to some individuals as the introduction and discussion questions had to be translated by the group facilitators to accommodate all participants. Despite these limitations, this study provided useful insight into the beliefs and practices of nutrition in pregnancy among ANC UTH clients.

\section{Conclusions}

The participants expressed willingness to accept new information regarding the need for essential fatty acids, particularly DHA, for the health of their infants during pregnancy and lactation. It was apparent that additional knowledge regarding the benefits of fish as a source of protein, vitamins, and essential fatty acids is needed as part of the nutrition and clinical services provided. Specifically, there should be education about including those types of fish that are high in DHA such as kapenta in the standard diet. As mentioned above, it is also critical to conduct additional studies to evaluate DHA supplementation as the RUSF-DHA for food insecure and malnourished women in pregnancy and lactation. For the well-nourished population, increased levels of DHA intake should be encouraged by counseling to eat kapenta and other high DHA-containing fish.

\section{Supplementary information}

Supplementary information accompanies this paper at https://doi.org/10. 1186/s12884-020-2783-8.

Additional file 1. The complete script of the focus group interviews.

\section{Abbreviations}

AA: arachidonic acid; ANC: antenatal clinic; BMI: Body Mass Index; DHA: docosahexaenoic acid; EPA: eicosapentaenoic acid; HIV: Human Immunodeficiency Virus; RUSF: Ready to use Supplemental Foods; RUTF: Ready to Use therapeutic Foods

\section{Acknowledgements}

A special thank you to all the women who agreed to participate and share their knowledge with this research team. The authors also wish to thank Mrs. Pauline Chiyabi, and Mr. Nathanael Wasamunu, for their assistance in screening and enrolling participants, as well as in facilitating the focus group sessions. We are also grateful to Prof Bellington Vwalika Head of Obstetrics and Gynaecology (UTH) for his support and mentoring supervision of MKL and MI. The assistance of Nicole Henretty Ilic and the team at Edesia is greatly appreciated for the development and production of the RUSF-DHA.

Authors' contributions

CD and CCL conceived study idea and provided technical oversight including data analysis and manuscript preparation. MKL and MI directed the focus group sessions and implemented data collection, entry and analysis at the UTH. SK 
and SM confirmed data entry of the focus group results and analysed the RUSF-DHA product at UNL. MW, CK and CW contributed expertise and oversight in data analysis. All authors participated throughout the stages of the study and contributed to manuscript preparation. All authors have read and approved the manuscript.

\section{Funding}

This work was carried out using support from the Nebraska Research Initiative; the US National Institutes of Health, National Cancer Institute award number U54 CA221204 to CW; the Fogarty International Center award number D43 TW010354 to CW; the UNL Undergraduate Creative Activities and Research Experience (UCARE) program and the UNL McNair Scholars Program. The funding body reviewed and approved the study proposal and experimental design; they did not have any role in data collection, analysis, interpretation of data or writing of this manuscript.

\section{Availability of data and materials}

The datasets generated and analyzed during the current study are not publicly available since participants did not give consent to publicly sharing their information, but summaries of the information are either included in the manuscript or available from the corresponding author on reasonable request.

\section{Ethics approval and consent to participate}

These studies were approved by Institutional Review Boards at each institution to comply with Zambian and US laws (UNZAREC IRB \#00005948 and UNL IRB \#20170416833FB). Informed consent was obtained from all participants at the time of the focus group sessions.

\section{Consent for publication}

The manuscript does not include any individual persons data; hence consent to publish is not applicable. The participants gave consent for the findings of the study to be published.

\section{Competing interests}

The authors declare that they have no competing interests.

\section{Author details}

${ }^{1}$ University Teaching Hospitals, Lusaka Children's Hospital, University of Zambia, School of Medicine, Lusaka, Zambia. ${ }^{2}$ University Teaching Hospitals, Women and Newborn Hospital, University of Zambia, School of Medicine, Lusaka, Zambia. ${ }^{3}$ Nebraska Center for Integrated Biomolecular Communications, Department of Biochemistry, N241 Beadle Center, University of Nebraska-Lincoln, Lincoln, NE 68588, USA. ${ }^{4}$ Department of Nutrition and Health Sciences, University of Nebraska-Lincoln, Lincoln, NE, USA. ${ }^{5}$ Nebraska Center for Virology, School of Biological Sciences, University of Nebraska-Lincoln, Lincoln, NE, USA.

\section{Received: 26 February 2019 Accepted: 30 January 2020} Published online: 10 February 2020

\section{References}

1. Central Statistical Office (CSO) [Zambia], Ministry of Health (MOH) [Zambia], and ICF International. Zambia Demographic and Health Survey 2013-14. Rockville: Central Statistical Office, Ministry of Health, and ICF International. 2014.

2. Banda-Nyirenda D, Hüsken SMC, Kaunda W. Impact of nutrition and fish supplementation on the response to Anti Retroviral Therapy, Zambia. A literature review. Regional Programme Fisheries and HIV/AIDS in Africa: Investing in Sustainable Solutions. The WorldFish Center. Project Report 1985. 2009.

3. Kelly P, Saloojee H, Chen JY, Chung RT. Noncommunicable diseases in HIV infection in low- and middle-income countries: gastrointestinal, hepatic, and nutritional aspects. J Acquir Immune Defic Syndr. 2014;67(Suppl 1):S79-86.

4. Richards K, Bellak S: Malnutrition in Zambia: harnessing social protection for the most vulnerable. Save The Children UK. 2016.https://resourcecentre.savethe children.net/authors/bellack-stephanie?f[0]=sm_document_type\%3Apdf.

5. Marinda PA, Genschick S, Khayeka-Wandabwa C, Kiwanuka-Lubinda R, Thilsted $\mathrm{SH}$. Dietary diversity determinants and contribution of fish to maternal and under-five nutritional status in Zambia. PLoS One. 2018;13(9):e0204009.

6. Gitau R, Makasa M, Kasonka L, Sinkala M, Chintu C, Tomkins A, Filteau S. Maternal micronutrient status and decreased growth of Zambian infants born during and after the maize price increases resulting from the southern African drought of 2001-2002. Public Health Nutr. 2005;8(7):837-43.

7. Steiner-Asiedu M, Lied E, Lie $\varnothing$, Nilsen R, Julshamn K. The nutritive value of sundried pelagic fish from the rift valley in Africa. J Sci Food Agric. 1993;63(4):439-43.

8. Schoonees A, Lombard M, Musekiwa A, Nel E, Volmink J. Ready-to-use therapeutic food for home-based treatment of severe acute malnutrition in children from six months to five years of age. Cochrane Database Syst Rev. 2013;(6):Cd009000.

9. de Pee S, Bloem MW. Current and potential role of specially formulated foods and food supplements for preventing malnutrition among 6- to 23month-old children and for treating moderate malnutrition among 6- to 59month-old children. Food Nutr Bull. 2009;30(3 Suppl):S434-63.

10. Chaparro CM, Dewey KG. Use of lipid-based nutrient supplements (LNS) to improve the nutrient adequacy of general food distribution rations for vulnerable sub-groups in emergency settings. Matern Child Nutr. 2010; 6(Suppl 1):1-69.

11. Dewey KG, Arimond M. Lipid-based nutrient supplements: how can they combat child malnutrition? PLoS Med. 2012;9(9):e1001314.

12. Lazzerini $M$, Rubert $L$, Pani $P$. Specially formulated foods for treating children with moderate acute malnutrition in low- and middle-income countries. Cochrane Database Syst Rev. 2013;6:CD009584.

13. Arterburn LM, Hall EB, Oken H. Distribution, interconversion, and dose response of n-3 fatty acids in humans. Am J Clin Nutr. 2006;83(6 Suppl):1467S-76S.

14. Brenna JT, Carlson SE. Docosahexaenoic acid and human brain development: evidence that a dietary supply is needed for optimal development. J Hum Evol. 2014;77:99-106.

15. Innis SM. Impact of maternal diet on human milk composition and neurological development of infants. Am J Clin Nutr. 2014;99(3):734S-41S.

16. Mulder KA, King DJ, Innis SM. Omega-3 fatty acid deficiency in infants before birth identified using a randomized trial of maternal DHA supplementation in pregnancy. PLoS One. 2014;9(1):e83764.

17. Bazzano AN, Potts KS, Bazzano LA, Mason JB. The life course implications of ready to use therapeutic food for children in low-income countries. Int J Environ Res Public Health. 2017;14(403):1-19.

18. Brenna JT, Akomo P, Bahwere P, Berkley JA, Calder PC, Jones KD, Liu L, Manary M, Trehan I, Briend A. Balancing omega- 6 and omega-3 fatty acids in ready-to-use therapeutic foods (RUTF). BMC Med. 2015;13:117.

19. Halcomb EJ, Gholizadeh L, DiGiacomo M, Phillips J, Davidson PM. Literature review: considerations in undertaking focus group research with culturally and linguistically diverse groups. J Clin Nurs. 2007;16(6):1000-11.

20. Hsieh HF, Shannon SE. Three approaches to qualitative content analysis. Qual Health Res. 2005;15(9):1277-88.

21. Arimond M, Zeilani M, Jungjohann S, Brown KH, Ashorn P, Allen LH, Dewey KG. Considerations in developing lipid-based nutrient supplements for prevention of undernutrition: experience from the international lipid-based nutrient supplements (iLiNS) project. Matern Child Nutr. 2015;11(Suppl 4):31-61.

22. Carlson SE, Colombo J, Gajewski BJ, Gustafson KM, Mundy D, Yeast J, Georgieff MK, Markley LA, Kerling EH, Shaddy DJ. DHA supplementation and pregnancy outcomes. Am J Clin Nutr. 2013;97(4):808-15.

23. Sealls W, Gonzalez M, Brosnan MJ, Black PN, DiRusso CC. Dietary polyunsaturated fatty acids (C18:2 omega6 and C18:3 omega3) do not suppress hepatic lipogenesis. Biochim Biophys Acta. 2008;1781(8):406-14.

24. Adu-Afarwuah S, Lartey A, Dewey KG. Meeting nutritional needs in the first 1000 days: a place for small-quantity lipid-based nutrient supplements. Ann N Y Acad Sci. 2017;1392(1):18-29.

25. Gundacker C, Kutalek R, Glaunach R, Deweis C, Hengstschlager M, Prinz A. Geophagy during pregnancy: is there a health risk for infants? Environ Res. 2017;156:145-7.

26. Abu BAZ, van den Berg VL, Raubenheimer JE, Louw VJ. Pica practices among apparently healthy women and their young children in Ghana. Physiol Behav. 2017;177:297-304.

27. Strobel C, Jahreis G, Kuhnt K. Survey of $n-3$ and $n-6$ polyunsaturated fatty acids in fish and fish products. Lipids Health Dis. 2012;11:144.

28. Robert A, Mfilinge P, Limbu SM, Mwita CJ. Fatty acid composition and levels of selected polyunsaturated fatty acids in four commercial important freshwater fish species from Lake Victoria, Tanzania. J Lipids. 2014;2014:712134.

29. Maleta K, Amadi B. Community-based management of acute malnutrition (CMAM) in sub-Saharan Africa: case studies from Ghana, Malawi, and Zambia. Food Nutr Bull. 2014;35(2 Suppl):S34-8.

30. Nel E. Severe acute malnutrition. Curr Opin Clin Nutr Metab Care. 2018;21(3):195-9.

31. Robinson DT, Caplan M, Carlson SE, Yoder R, Murthy K, Frost B. Early docosahexaenoic and arachidonic acid supplementation in extremely-lowbirth-weight infants. Pediatr Res. 2016;80(4):505-10. 
32. Foiles AM, Kerling EH, Wick JA, Scalabrin DM, Colombo J, Carlson SE. Formula with long-chain polyunsaturated fatty acids reduces incidence of allergy in early childhood. Pediatr Allergy Immunol. 2016;27(2):156-61.

33. Currie LM, Tolley EA, Thodosoff JM, Kerling EH, Sullivan DK, Colombo J, Carlson SE. Long chain polyunsaturated fatty acid supplementation in infancy increases length- and weight-for-age but not BMI to 6 years when controlling for effects of maternal smoking. Prostaglandins Leukot Essent Fatty Acids. 2015;98:1-6.

34. Tam EW, Chau V, Barkovich AJ, Ferriero DM, Miller SP, Rogers EE, Grunau RE, Synnes AR, Xu D, Foong J, et al. Early postnatal docosahexaenoic acid levels and improved preterm brain development. Pediatr Res. 2016;79(5):723-30.

35. Innis SM. Dietary omega 3 fatty acids and the developing brain. Brain Res. 2008;1237:35-43.

36. Yelland LN, Gajewski BJ, Colombo J, Gibson RA, Makrides M, Carlson SE. Predicting the effect of maternal docosahexaenoic acid (DHA) supplementation to reduce early preterm birth in Australia and the United States using results of within country randomized controlled trials. Prostaglandins Leukot Essent Fatty Acids. 2016;112:44-9.

37. Meher A, Randhir K, Mehendale S, Wagh G, Joshi S. Maternal fatty acids and their association with birth outcome: a prospective study. PLoS One. 2016;11(1):e0147359.

38. Vidakovic AJ, Gishti O, Steenweg-de Graaff J, Williams MA, Duijts L, Felix JF, Hofman A, Tiemeier H, Jaddoe WW, Gaillard R. Higher maternal plasma n-3 PUFA and lower n-6 PUFA concentrations in pregnancy are associated with lower childhood systolic blood pressure. J Nutr. 2015;145(10):2362-8.

39. Adu-Afarwuah S, Lartey A, Okronipa H, Ashorn P, Ashorn U, Zeilani M, Arimond M, Vosti SA, Dewey KG. Maternal supplementation with smallquantity lipid-based nutrient supplements compared with multiple micronutrients, but not with Iron and folic acid, reduces the prevalence of low gestational weight gain in semi-urban Ghana: a randomized controlled trial. J Nutr. 2017;147(4):697-705.

40. Adams KP, Ayifah E, Phiri TE, Mridha MK, Adu-Afarwuah S, Arimond M, Arnold CD, Cummins J, Hussain S, Kumwenda C, et al. Maternal and child supplementation with lipid-based nutrient supplements, but not child supplementation alone, decreases self-reported household food insecurity in some settings. J Nutr. 2017;147(12):2309-18

41. Adu-Afarwuah S, Lartey A, Okronipa H, Ashorn P, Zeilani M, Peerson JM, Arimond M, Vosti S, Dewey KG. Lipid-based nutrient supplement increases the birth size of infants of primiparous women in Ghana. Am J Clin Nutr. 2015;101(4):835-46.

42. Adu-Afarwuah S, Lartey A, Okronipa H, Ashorn P, Peerson JM, Arimond M, Ashorn U, Zeilani M, Vosti S, Dewey KG. Small-quantity, lipid-based nutrient supplements provided to women during pregnancy and 6 mo postpartum and to their infants from $6 \mathrm{mo}$ of age increase the mean attained length of 18-mo-old children in semi-urban Ghana: a randomized controlled trial. Am J Clin Nutr. 2016;104(3):797-808.

43. Moramarco S, Amerio G, Ciarlantini C, Chipoma JK, Simpungwe MK, NielsenSaines K, Palombi L, Buonomo E. Community-based Management of Child Malnutrition in Zambia: HIV/AIDS infection and other risk factors on child survival. Int J Environ Res Public Health. 2016;13(7):666.

44. Craddock JC, Neale EP, Probst YC, Peoples GE. Algal supplementation of vegetarian eating patterns improves plasma and serum docosahexaenoic acid concentrations and omega-3 indices: a systematic literature review. J Hum Nutr Diet. 2017;30(6):693-9.

45. Deckelbaum RJ, Torrejon C. The omega-3 fatty acid nutritional landscape: health benefits and sources. J Nutr. 2012;142(3):587s-91s.

46. Marine Oils. In: Drugs and Lactation Database (LactMed). edn. Bethesda (MD): National Library of Medicine (US); 2006.

47. Morse NL. Benefits of docosahexaenoic acid, folic acid, vitamin D and iodine on foetal and infant brain development and function following maternal supplementation during pregnancy and lactation. Nutrients. 2012;4(7):799-840.

48. Jones KD, Ali R, Khasira MA, Odera D, West AL, Koster G, Akomo P. Talbert AW, Goss VM, Ngari M, et al. Ready-to-use therapeutic food with elevated $n$ 3 polyunsaturated fatty acid content, with or without fish oil, to treat severe acute malnutrition: a randomized controlled trial. BMC Med. 2015;13:93.

49. Jimenez EY, Mangani C, Ashorn P, Harris WS, Maleta K, Dewey KG. Breast milk from women living near Lake Malawi is high in docosahexaenoic acid and arachidonic acid. Prostaglandins Leukot Essent Fatty Acids. 2015;95:71-8.

\section{Publisher's Note}

Springer Nature remains neutral with regard to jurisdictional claims in published maps and institutional affiliations.

\section{Ready to submit your research? Choose BMC and benefit from:}

- fast, convenient online submission

- thorough peer review by experienced researchers in your field

- rapid publication on acceptance

- support for research data, including large and complex data types

- gold Open Access which fosters wider collaboration and increased citations

- maximum visibility for your research: over $100 \mathrm{M}$ website views per year

At BMC, research is always in progress.

Learn more biomedcentral.com/submissions 